\title{
Effect of Process Parameters on Deposition Properties of Functionally Graded STS 316/Fe Manufactured by Laser Direct Metal Deposition
}

\author{
Sangwoo Nam ${ }^{1}$ (D), Heewon Cho ${ }^{1,2}$, Cheolhee $\mathrm{Kim}^{1}{ }^{1(\mathbb{D})}$ and Young-Min Kim ${ }^{1, *(1)}$ \\ 1 Joining R\&D Group, Korea Institute of Industrial Technology, 156 Gaetbeol-ro(Songdo-dong), Yeonsu-Gu, \\ Incheon 21999, Korea; chak1843@kitech.re.kr (S.N.), hee95@kitech.re.kr (H.C.), chkim@kitech.re.kr (C.K.) \\ 2 Department of Mechanical Design Engineering, Hanyang University, 222 Wangsimni-ro, Seoul 04763, Korea \\ * Correspondence: ymkim77@kitech.re.kr; Tel.: +82-32-850-0232
}

Received: 17 July 2018; Accepted: 2 August 2018; Published: 4 August 2018

\begin{abstract}
Stainless steel 316 (STS316)/Fe functionally graded materials were fabricated by direct energy deposition (DED) method using laser as a heat source. The feeding amount of the mixed powder was evaluated and the powder feeding condition was optimized through the section evaluation. The reliability of the powder feed was evaluated by regression analysis, and it was confirmed through the energy dispersive spectrometer (EDS) analysis and X-ray diffractometer (XRD) that the graded functional material of the designed composition was manufactured. Defects and microstructures were analyzed by scanning electron microscope (SEM).
\end{abstract}

Keywords: functionally graded materials; directed energy deposition; STS316; laser; additive manufacturing; crack

\section{Introduction}

With the development of laser processing technology, the additive manufacturing market is growing rapidly. Additive manufacturing process using lasers is highly precise, making it possible to manufacture complex parts and customized designs. In addition, because the production speed is high and the post-processing such as molding and cutting is simplified, the material and cost required for the process can be reduced. Accordingly, it has recently been applied not only to aerospace fields such as turbine blades, combustors, and nozzles, but also to biomedical applications such as bioimplants [1]. There are two main processes of laser metal deposition, powder bed fusion (PBF) and direct energy deposition (DED). The PBF method, which is advantageous for achieving relatively precise shapes, is widely being applied. On the other hand, the DED method has high productivity because it has a fast stacking speed and less restriction in size. Therefore, this method is advantageous for improving the characteristics of existing parts or adding new functions to the metal base material through surface strengthening, repair, and remodeling.

Powder processing has high design opportunity and production flexibity, and laser processing has excellent quality and properties due to the fast heating and cooling rate resulting in formation of fine microstructures [2]. Thus, the DED process using powder and laser has a high potential to solve various issues occurring at the joints of dissimilar materials such as difference of melting temperature, mismatch from thermal expansion-contraction, galvanic corrosion, and formation of brittle intermetallic compounds [3]. As parameters of the process affect the quality, many studies have been conducted to obtain defect-free uniform material deposition by controlling the parameters of the deposited materials [4-6]. Goodarzi et al. [4] reported the influence of the laser cladding process parameters on the clad bead geometry using stainless steel (STS) powder. The laser power 
and cladding speed rate were the main parameters for controlling the clad layer width. Most of the deformation was at the clad height, but the clad bead side angle also depended on the powder feed rate and cladding speed. Saqib et al. [5] presented the result of laser cladding using P420 steel cladding powder deposited on low carbon structural steel plates. Process parameters such as laser power, scanning speed, and powder flow rate, among others, affected the bead height, width, penetration, area, dilution area, and bead shape. to process parameter relationships, the bead shape was analyzed using an artificial neural network (ANN). Calleja et al. [7,8] optimized the parameter value based on quantitative analysis and deviation of each parameters such as bead height, width, deposition rate, and wetting angle and assigned different weight factor to each parameters. In addition, the feed rate for uniform supply was controlled via the developed algorithm [8].

In the metallurgical point of view, another solution for issues of dissimilar joints is functionally graded materials (FGM) that gradually change the composition or properties. Including mild steel-STS FGM [9], various FGM such as Inconel-STS FGM [10,11], Ti6Al4V-STS FGM [12-15], Invar-STS FGM [16], and compositional gradient STS $[17,18]$ have been manufactured. Especially mild steel and STS are the most widely used materials in structural parts, requiring their dissimilar welds for pipes, valves, and pressure vessels [19]. However, the direct dissimilar joints cause defects at the interface, which originates from brittle phase formation, thermal deformation, solidification cracking, hydrogen cracking, porosity, and so on. Thus, it can lead to earlier failure than the expected life [20-22]. Li et. al. [13-15] used V, Cr, and Fe elemental powder to make an FGM between Ti6Al4V and STS, because directly additive manufacturing results in fracture by intermetallic phases, $\mathrm{FeTi}$ and $\mathrm{Fe}_{2} \mathrm{Ti}$. The Fe powder is employed in the transition zone between $\mathrm{Cr}$ and STS. Fe could be used for austenite-ferrite transition joints, but the brittle sigma phase at these interfaces should be controlled by adjusting the $\mathrm{Cr}$ content and cooling rate [13].

The FGM is fabricated with supplying powder by changing the ratio of powders. Spherical powders are utilized with narrow particle size distribution, because the powders have an excellent green density with a high filling rate, making it easy to manufacture dense samples with low porosity. In addition, when the particle diameter ratio is equal or close to an ideal value, all the particles will have the same velocity during feeding [23]. However, the irregular shape of the powder has a high probability of occurrence of porosity at the interface during the deposition process, and the velocity of particles will be different. There have been few studies about DED production technology from researching the process parameters using irregular particles to replacing dissimilar joint by the FGM manufacturing. Hwang et al. [24] evaluated and compared the physical and chemical properties for each size in the STS metal powder produced by water atomization and gas atomization using DED process. The authors presented the deposition results of metal powder by gas atomization, which were relatively better than that of metal powder by water atomization.

In this study, the dissimilar joint between mild steel and STS316 was fabricated as functionally graded materials through laser DED process. The influence of process paremeters on bead shape and welding defects was analyzed through laser single layer deposition using irregular Fe powder. STS316-Fe FGM were prepared by laser deposition on the surface of mild steel by mixing Fe and STS316 powder with various ratios. In addition, the direct deposition STS316 on mild steel was compared and analyzed with the FGM.

\section{Experimental Procedures}

Single layer depositions were carried out using Fe (water atomized powder, CNPC Powder) powder on the mild steel with $12 \mathrm{~mm}$ thickness. FGM depositions used the Fe powder and STS316 (gas atomized powder, Praxair) powder on the mild steel substrate. Table 1 shows the chemical composition of each powder. The powder was supplied using a powder feeder (Praxair 1264, Praxair, Concord, NH, USA). During the FGM deposition process, the mixed powders were prepared by ball mill equipment (HBM-800 4R, HANTECH, Gunpo, Korea) of Fe and STS316 at a weight ratio of 3:1, 1:1, and 1:3, respectively. In the ball milling process, a $10 \mathrm{~mm}$ diameter stainless steel ball was mixed XHD RY with 
each powder at a ratio of 10:1 and then mixed at a speed of $200 \mathrm{rpm}$ for $20 \mathrm{~h}$ to prepare a mixed powder. The experiments were carried out using a $4 \mathrm{~kW}$ Yb:YAG (Yb: $\left.\mathrm{Y}_{3} \mathrm{Al}_{5} \mathrm{O}_{12}\right)$ disk laser (HLD4002, Trumpf, Erlangen, Germany). In addition, an optical fiber with a diameter of $0.2 \mathrm{~mm}$, an optical system with a focal length of $220 \mathrm{~mm}$, and a laser head coaxially injected with a laser were used. Defocusing the focal point over the base material was used to create a laser beam with a diameter of $3.5 \mathrm{~mm}$. Figure $1 \mathrm{a}$ shows the schematic diagram of the experimental setup, and Figure $1 \mathrm{~b}$ indicates the nozzle part where powders are supplied. The powders are distributed in three ways and are concentrically supplied around the laser beam via the space between the inner cap and the outer cap of nozzle. The laser power, feed rate, injection speed, beam shift, and contact tip to work-piece distance (CTWD) were varied in the evaluation of the single layer deposition. The range of each process parameters and the deposition conditions are shown in Table 2.

Table 1. Chemical composition of powders used in this study.

\begin{tabular}{ccccccccccc}
\hline Powder & Fe & C & O & Si & Mn & P & S & Ni & Cr & Mo \\
\hline STS316 & Bal. & 0.02 & 0.03 & 0.01 & 1.06 & 0.005 & 0.003 & 12.00 & 17.00 & 2.04 \\
Fe & Bal. & 0.01 & 0.15 & 0.08 & 0.13 & 0.008 & 0.006 & 0.005 & 0.005 & 0.003 \\
\hline
\end{tabular}

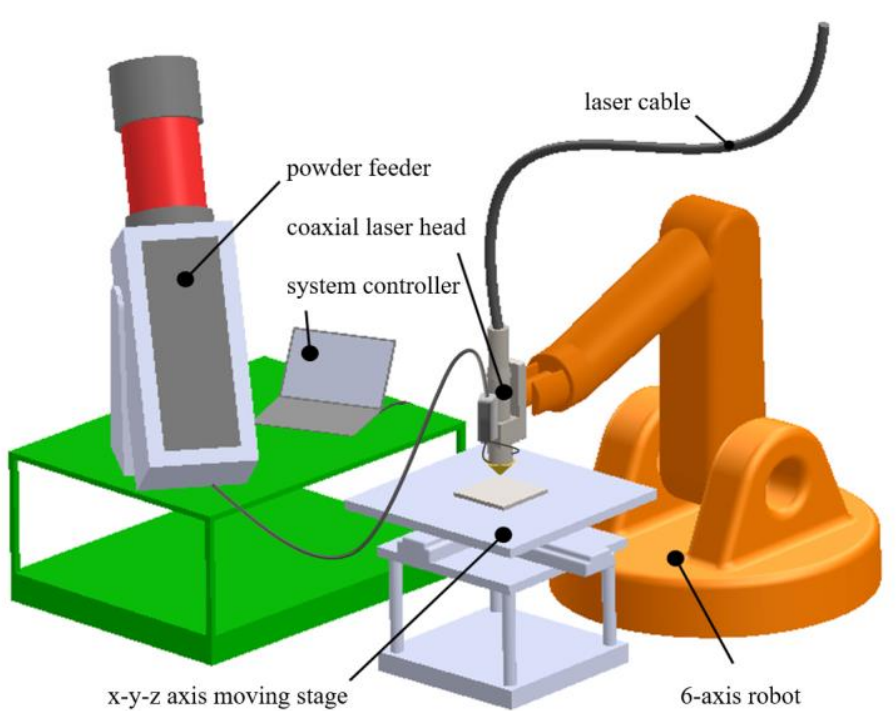

(a)

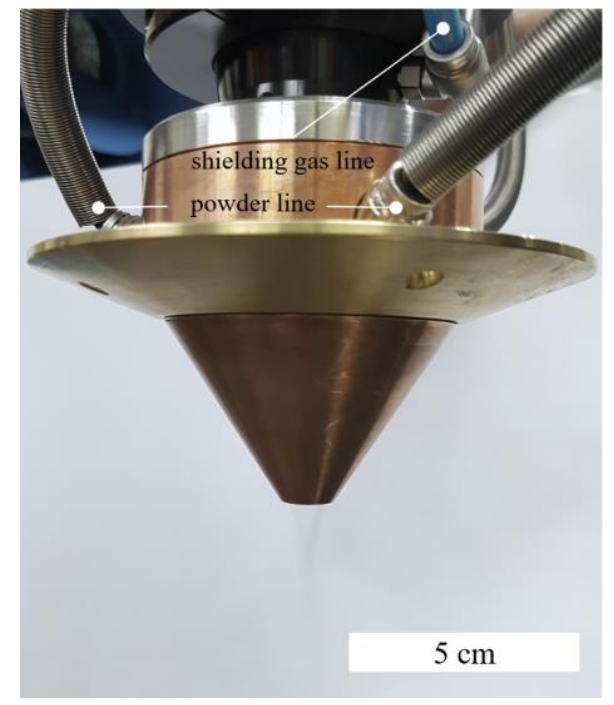

(b)

Figure 1. (a) Schematic diagram of experimental setup and (b) image of coaxial nozzle.

Table 2. Various parameters for deposition used in this study.

\begin{tabular}{ccc}
\hline Process Parameter & Single Pass & Build Production \\
\hline Laser Power $(\mathrm{kW})$ & $0.5-2.5[2]$ & 2 \\
Travel speed $(\mathrm{m} / \mathrm{s})$ & $0.001-0.01[0.005]$ & 0.0083 \\
Flow rate $(\mathrm{g} / \mathrm{min})$ & $15-30[20]$ & 30 \\
Beam Shift $(\mathrm{mm})$ & $0-2[0]$ & 0 \\
Contact tip to work-piece distance $(\mathrm{mm})$ & $5-15[10]$ & $10-11$ \\
Shielding gas $(\mathrm{L} / \mathrm{min})$ & $15(\mathrm{Ar})$ & $15(\mathrm{Ar})$ \\
Carrier gas $(\mathrm{L} / \mathrm{min})$ & $10(\mathrm{Ar})$ & $10(\mathrm{Ar})$ \\
\hline
\end{tabular}

A six-axis robot (KR 100-3, Kuka, Augsburg, Germany) and a stage capable of moving in the $x-y-z$ axis were used for deposition process. The two kinds of deposited specimens were fabricated by 
deposition of five layers with a length of $55 \mathrm{~mm}$, with six passes per layer; the details of deposition conditions are shown in the Table 3. Microstructures and processes were also analyzed using optical microscope (OM, BX51M, Olympus, Tokyo, Japan) and field emission scanning electron microscopy (FE-SEM, Quanta200F, Themo Fisher, Eindhoven, The Netherlands). The phase analysis of sample 2 was performed by X-ray diffractometer (XRD, MiniFlex, Rigaku, Japan) using monochromatic $\mathrm{Cu}-\mathrm{K}_{\alpha}$ radiation $(\lambda=0.154056 \mathrm{~nm})$.

Table 3. Deposition sequence used in this study.

\begin{tabular}{|c|c|c|c|}
\hline \multirow[t]{2}{*}{ Sample } & \multirow{2}{*}{$\begin{array}{c}\text { Sample } 1 \\
\text { (Dissimilar Welding) } \\
\text { Composition (wt \%) }\end{array}$} & \multicolumn{2}{|c|}{$\begin{array}{c}\text { Sample } 2 \\
\text { (Functionally Graded Materials) }\end{array}$} \\
\hline & & Composition (wt \%) & Layer Name \\
\hline 5th layer & STS316 & $100 \%$ STS316 & OFe \\
\hline 4th layer & STS316 & $75 \%$ STS $316+25 \% \mathrm{Fe}$ & $25 \mathrm{Fe}$ \\
\hline 3rd layer & STS316 & $50 \%$ STS $316+50 \% \mathrm{Fe}$ & $50 \mathrm{Fe}$ \\
\hline 2nd layer & STS316 & $75 \%$ STS $316+25 \% \mathrm{Fe}$ & $75 \mathrm{Fe}$ \\
\hline 1st layer & STS316 & $100 \% \mathrm{Fe}$ & $100 \mathrm{Fe}$ \\
\hline Substrate & Mild steel & \multicolumn{2}{|c|}{ Mild steel } \\
\hline
\end{tabular}

\section{Results and Discussion}

\subsection{Effect of Process Parameters on the Bead Geometry}

In order to investigate the effect of process parameters on the bead geometry during the deposition process, a single layer was deposited with Fe powder on mild steel and various properties were evaluated. Most of the STS316 powder (99 wt \%) is distributed in the size range from 44 to $150 \mu \mathrm{m}$, but the Fe powder is $77 \mathrm{wt} \%$ in the range as shown in Table 4. Regarding Fe powder, $21 \mathrm{wt} \%$ has a size of less than $44 \mu \mathrm{m}$, which is consistent with the presence of a large amount of small particles in Figure 2a,b. Thus, Fe powders have a wide distribution range and a non-uniform shape. On the other hand, STS 316 powder was powder with a spherical shape of between 44 and $150 \mu \mathrm{m}$, as shown in Figure 2.

Table 4. Powder distribution measeured by sieve analysis.

\begin{tabular}{cccc}
\hline \multirow{2}{*}{ Sieve Number } & \multirow{2}{*}{ Particle Size $(\mu \mathrm{m})$} & \multicolumn{2}{c}{ Distribution (wt \%) * } \\
\cline { 3 - 4 } & & Fe & STS316 \\
\hline 100 & $>150$ & 2 & - \\
140 & $105-150$ & 18 & 99 \\
200 & $74-105$ & 29 & \\
325 & $44-74$ & 30 & 1 \\
-325 & $<44$ & 21 & \\
\hline
\end{tabular}

* Analysis reults from powder supplier 


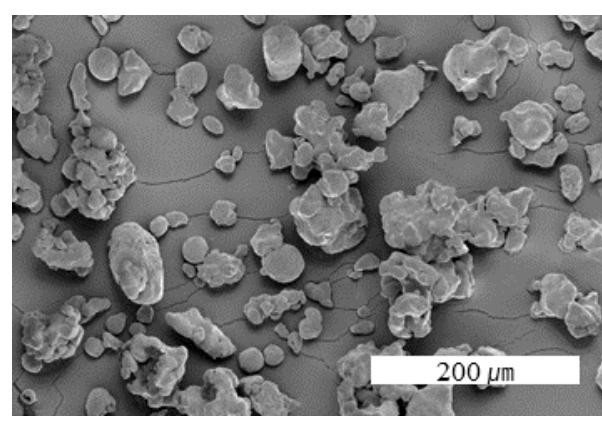

(a)

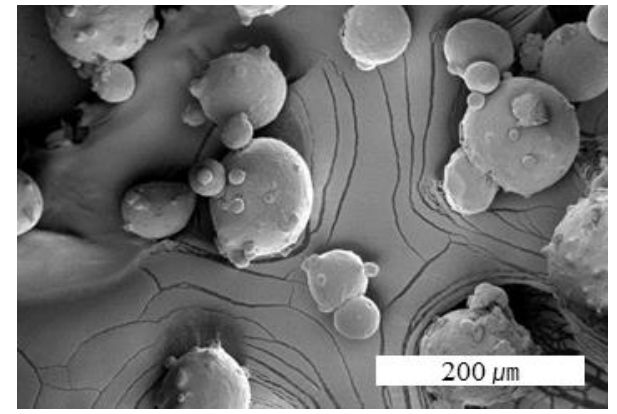

(c)

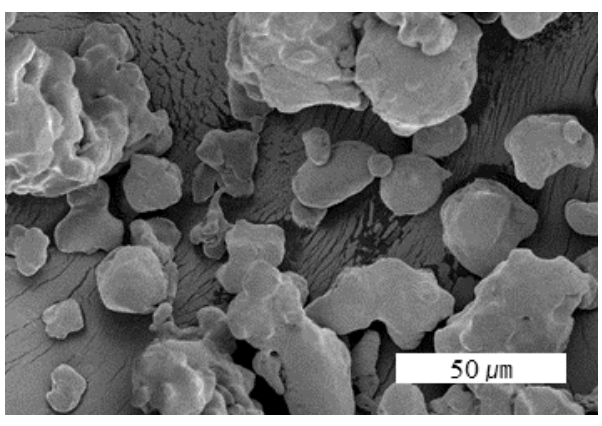

(b)

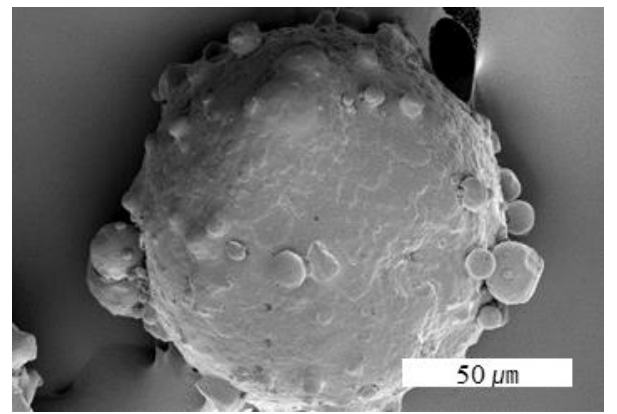

(d)

Figure 2. FE-SEM images for powder morphology. (a) Fe powder at low magnification, (b) Fe powder at high magnification, (c) STS316 at low magnification, and (d) STS316 at high magnification.

\subsubsection{Contact Tip to Work-Piece Distance}

Figure 3 shows a cross-section of the beads deposited under various CTWD from $5 \mathrm{~mm}$ to $15 \mathrm{~mm}$. When the CTWD was $5 \mathrm{~mm}$, the shape of the beads could not be formed properly, because of the CTWD, the shielding gas and the carrier gas were concentrated in a narrow region and affected the bead shape. In addition, large pores were trapped inside, as shown in Figure 3a. In the case of CTWD of $7 \mathrm{~mm}$, the bead appearance was good, but as in the case of CTWD of $5 \mathrm{~mm}$, large pores were formed inside (Figure 3b). In the case of CTWD of $9 \mathrm{~mm}$, pores were generated inside, but the pore size was smaller than that of $7 \mathrm{~mm}$, as shown in Figure 3c. This is because the CTWD increases and the gas pressure on the bead surface decreases. In the CTWD of $11 \mathrm{~mm}$ or more, pores inside the beads were almost removed (Figure 3d-f). As shown in the case of $13 \mathrm{~mm}$ and $15 \mathrm{~mm}$, the bead height was increased as the CTWD was increased. In the CTWD, the powder was concentrated in the center, and the beads fell off during processing due to the lack of fusion. As shown in the case of CTWD of $13 \mathrm{~mm}$ and $15 \mathrm{~mm}$, the bead height increased as the CTWD increased. In the CTWD of $15 \mathrm{~mm}$ or more, the powder was concentrated at the center, and the beads were separated from the base material during processing due to the lack of fusion. In order to obtain a good bead shape, it is important to reduce the influence of the gas pressure and to prevent the lack of fusion. 


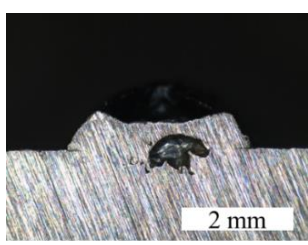

(a)

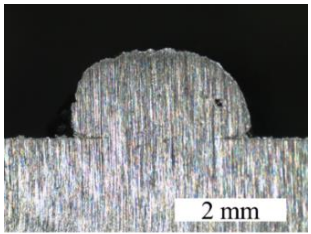

(d)

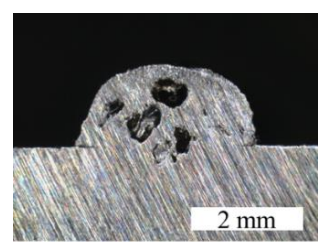

(b)

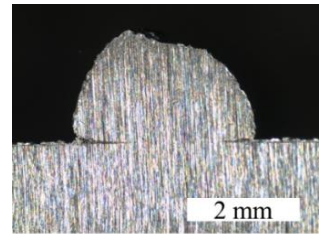

(e)

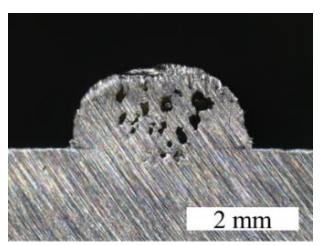

(c)

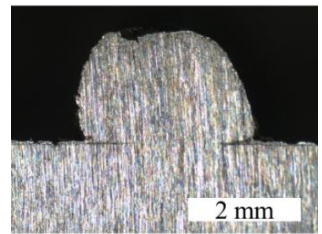

(f)

Figure 3. Cross section of bead with various contact tip to work-piece distance (a) $5 \mathrm{~mm}$, (b) $7 \mathrm{~mm}$, (c) $9 \mathrm{~mm},(\mathbf{d}) 11 \mathrm{~mm},(\mathbf{e}) 13 \mathrm{~mm}$, and (f) $15 \mathrm{~mm}$.

\subsubsection{Beam Shift}

In the laser cladding process, it is generally desired to obtain a good bead by matching the focus of the beam and the powder injection. However, in order to completely cladd the surface, the bead shape of the previous pass is influenced because the multiple passes are overlapped. In addition, when applied to various geometric shapes of base material and welds, techniques are needed to fill various spaces. Therefore, various beam angle or bead shape generation through beam movement was investigated. Figures 4 and 5 show the schematic diagram of beam alignment and cross-section of the bead according to the shift distance of beam, respectively. When the beam shift distance is $0.5 \mathrm{~mm}$ (Figure $4 \mathrm{~b}$ ), the beads are asymmetrically formed in the direction of overlapping the beam and powder injection, and then the angle of the back surface increases to $120^{\circ}$. The large angle of the back surface can more effectively control the formation of pores when the next pass is overlapped and cladded. As the amount of powder overlapping between the powder and the beam was larger than when the beam was at the center, the cross-sectional area of the entire bead was increased. However, when the shift distance is $1.0 \mathrm{~mm}$, as shown in Figure $5 \mathrm{c}$, a bead with a certain height is formed on one side, but there are many pores inside. The generation of these pores is due to the asymmetric heat input of the laser beam. When the shift distance of the beam is $2.0 \mathrm{~mm}$, a high enough height of the bead for stacking cannot be obtained, as shown in Figure $5 \mathrm{~d}$ and pores were inside the bead. As the alignment of the beam and the powder was significantly shifted, the powders did not enter the molten pool and were dispersed into spatters. The asymmetry of the bead increases as the focus of the beam and the powder injection increases, and the angle of the back surface changes and the pore increases inside the bead.

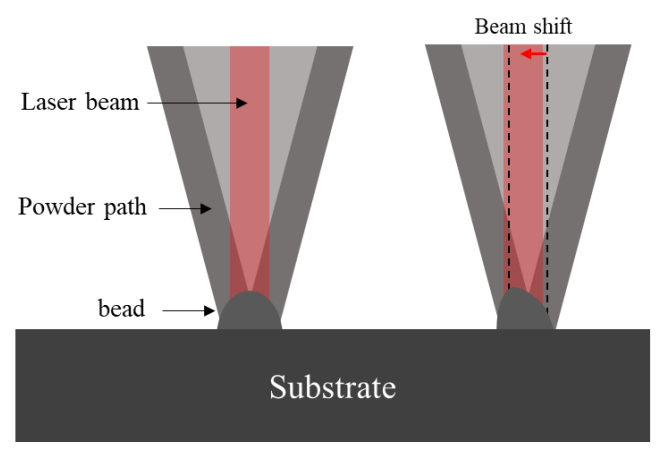

(a)

(b)

Figure 4. Schematic diagram of beam alignment: (a) center beam, (b) $0.5 \mathrm{~mm}$ shifted beam. 


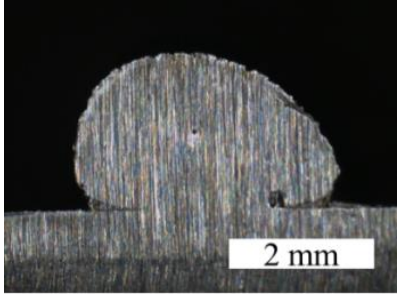

(a)

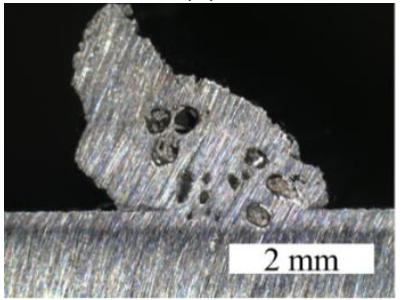

(c)

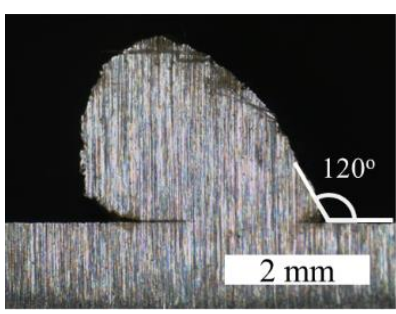

(b)

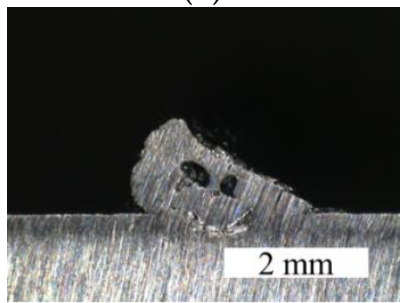

(d)

Figure 5. Cross-section of bead with various shift distance of beam (a) $0 \mathrm{~mm}$, (b) $0.5 \mathrm{~mm}$, (c) $1 \mathrm{~mm}$, and (d) $2 \mathrm{~mm}$.

\subsubsection{Laser Power}

The correlation between the laser power and the shape factor, such as height and width of the bead, is shown in Figure 6. As shown in Figure 6, the bead height and width increased with increasing laser power. When the bead ratio (height/width) was calculated, the laser power also increased the bead ratio. Thus, as shown in the bead ratio, the height of the bead was more influenced by the increase of the laser power.

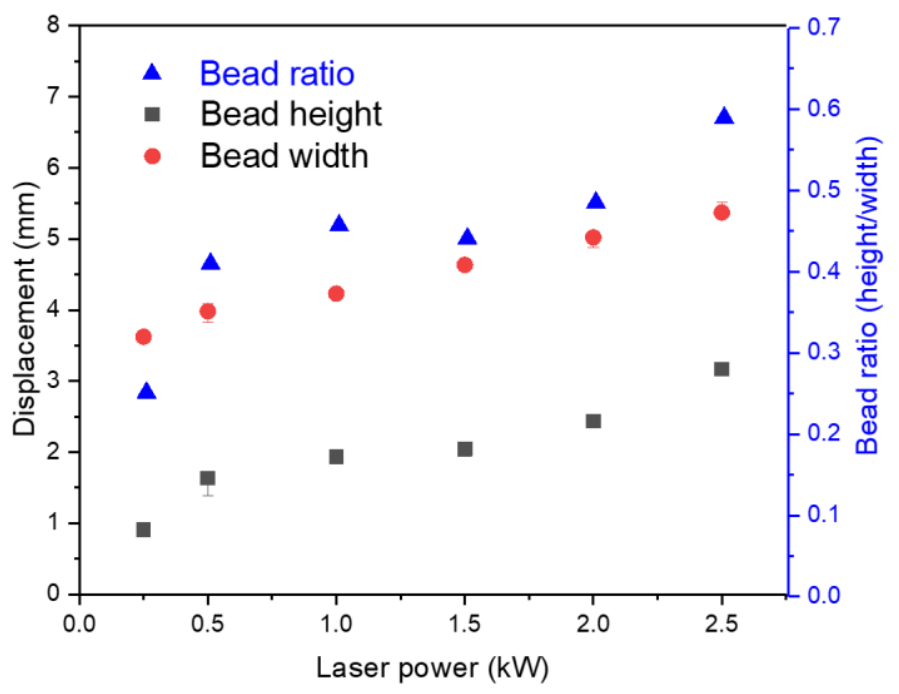

Figure 6. Bead height, width, and aspect ratio with various laser power.

Figure 7 shows the shape and cross-section of the bead according to the laser power. In the case of laser power of $0.5 \mathrm{~kW}$ and $1.0 \mathrm{~kW}$, lack of fusion occurred due to insufficient heat input, and bead was separated from base material and sound bead could not be obtained. When the laser power is $1.5 \mathrm{~kW}$, the bead shape spreads sideways and becomes lower in height. When the laser power increases to $2.0 \mathrm{~kW}$, a sound bead shape can be obtained. As the laser power increased to $2.5 \mathrm{~kW}$, the height and width of the bead became larger, but the pores existed in the upper part of the bead. The reason for this is that the melting pool is formed obliquely and the upper part is formed after the lower part. 
Therefore, the powders caught in the melting pool late at the upper part are solidified before being sufficiently densified.

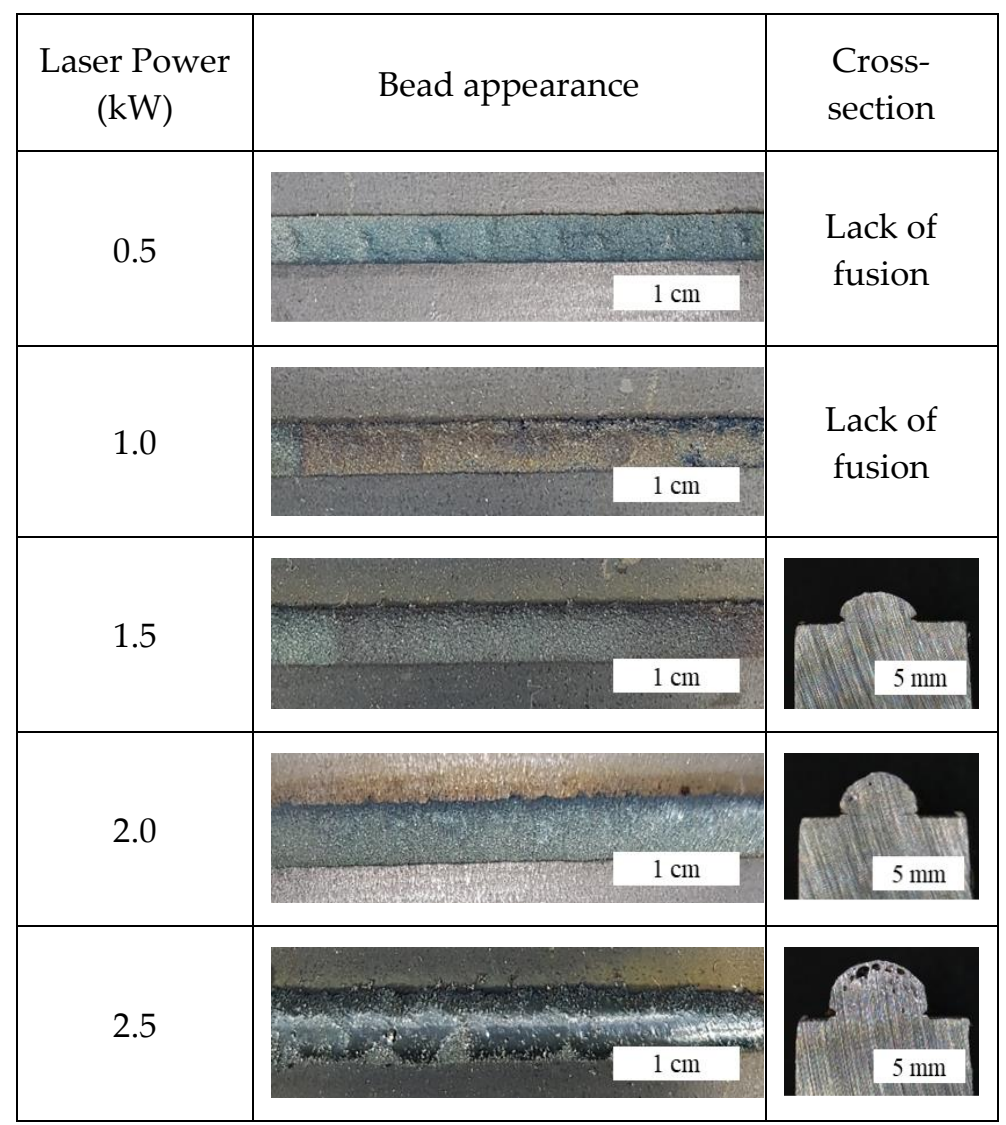

Figure 7. Bead appearance and cross-section of bead with various laser power from $0.5 \mathrm{~kW}$ to $2.5 \mathrm{~kW}$.

\subsubsection{Flow Rate}

Figures 8 and 9 show the bead height, width, and aspect ratio values and bead appearance and cross-section of bead according to the flow rate, respectively. As shown in Figure 8, the height and width of the beads increase slightly as the flow rate increases. In the area where the sound beads are generated, the aspect ratio did not greatly vary between $0.4-0.5$. When the flow rate is 15.0 , the amount of powder supplied is insufficient and puckering phenomenon occurs, so that a sound bead cannot be obtained, as shown in Figure 9. At a flow rate of 18.8, a sound bead could be obtained, but some pores were observed. When the flow rate was above 22.5 , a sound bead with no pores inside the bead was obtained. As the flow rate is increased, the amount of powder to be injected increases proportionally, but the volume of the bead is maintained and the efficiency of the deposition is deteriorated. Therefore, the flow rate condition is required to be selected in consideration of the deposition efficiency of the powder. 


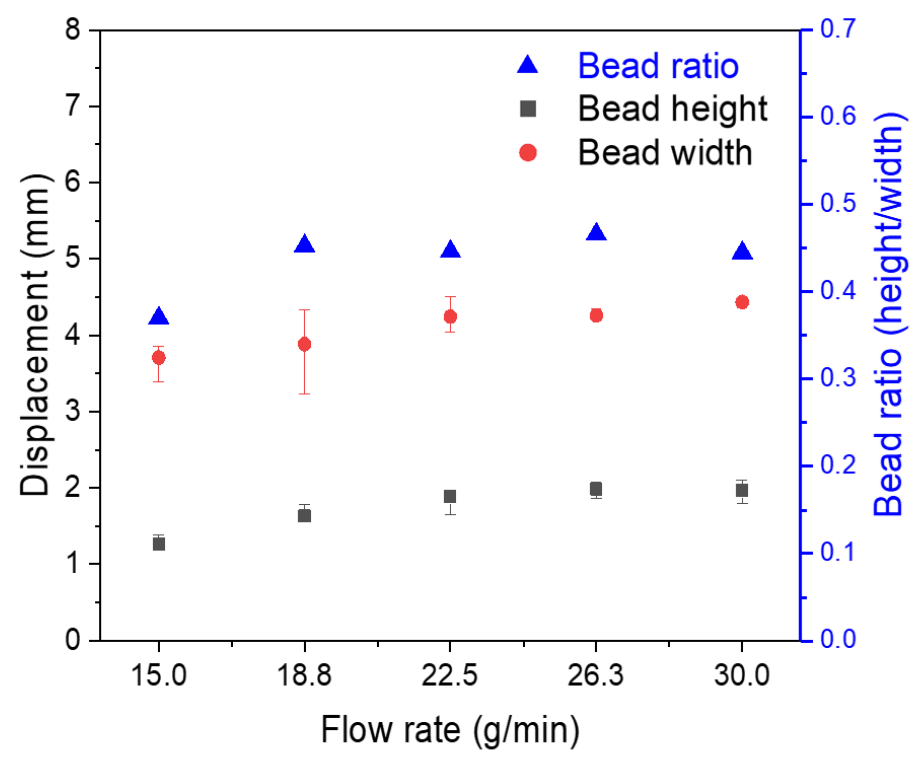

Figure 8. Bead height, width, and aspect ratio with various flow rates of Fe powder.

\begin{tabular}{|c|c|c|}
\hline $\begin{array}{l}\text { Flow rate } \\
\text { (g/min) }\end{array}$ & Bead appearance & $\begin{array}{l}\text { Cross- } \\
\text { section }\end{array}$ \\
\hline 15.0 & 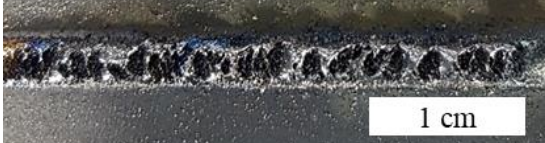 & $5 \mathrm{~mm}$ \\
\hline 18.8 & (1) & $5 \mathrm{~mm}$ \\
\hline 22.5 & $1 \mathrm{~cm}$ & $5 \mathrm{~mm}$ \\
\hline 26.3 & $1 \mathrm{~cm}$ & $5 \mathrm{~mm}$ \\
\hline 30.0 & $1 \mathrm{~cm}$ & \\
\hline
\end{tabular}

Figure 9. Bead appearance and cross-section of bead with various flow rate from 15.0 to $30.0 \mathrm{~g} / \mathrm{min}$.

\subsubsection{Travel Speed}

As the travel speed increases, the bead height and width tend to decrease. As shown in Figure 10, when the travel speed is increased from $0.1 \mathrm{~cm} / \mathrm{s}$ to $0.3 \mathrm{~cm} / \mathrm{s}$, the height and width of the bead decrease sharply, and thereafter the decrease is reduced. Also, the deviation in the height and width of the beads increased at speeds of lower than $0.2 \mathrm{~cm} / \mathrm{s}$ or higher than $0.9 \mathrm{~cm} / \mathrm{s}$. The formation of internal pores due to the humping beads at high speed and at low speeds also affects the bead appearance. 


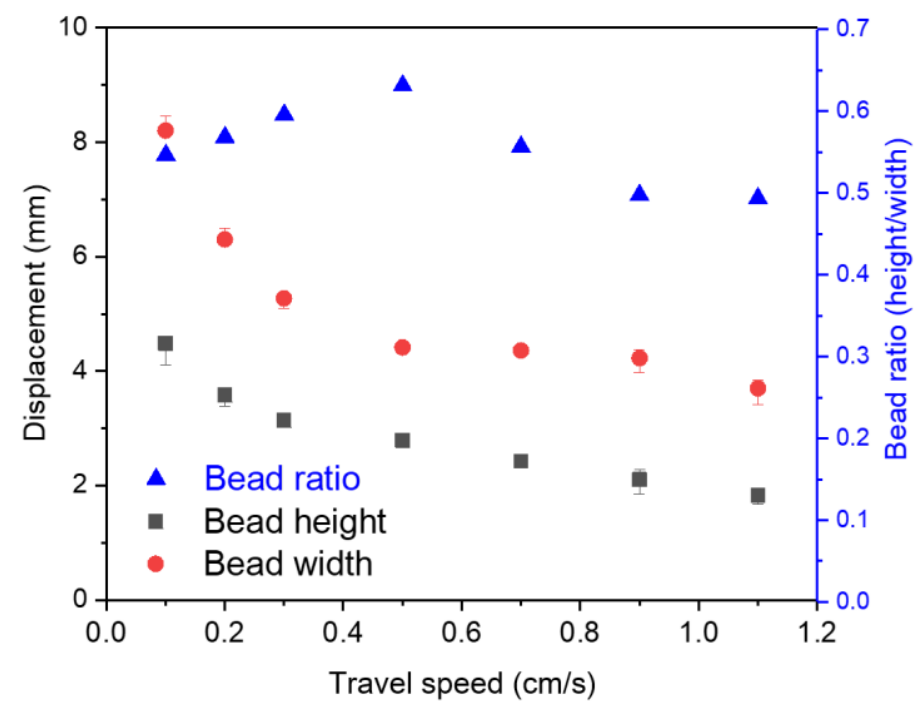

Figure 10. Bead height, width, and aspect ratio with various travel speed.

Figure 11 shows the bead appearance and cross-section of the bead at various travel speeds. The molten pool generated by the laser cladding has a large temperature gradient and surface tension, which forms a high fluid flow [25]. When travel speed is low, such as $0.1 \mathrm{~cm} / \mathrm{s}$, the temperature gradient and surface tension are reduced by the high heat input as fluid flow decreases, forming a hump surface. As the travel speed increased to 0.3 and $0.5 \mathrm{~cm} / \mathrm{s}$, a sound bead with no porosity was obtained. Also, by changing the travel speed, a defect-free bead with a high bead ratio of 0.65 was obtained. However, when the travel speed was $0.9 \mathrm{~cm} / \mathrm{s}$, the bead appearance seemed to be sound, but pores were observed inside. In the case of travel speed of $1.1 \mathrm{~cm} / \mathrm{s}$, pores were observed both inside and outside of the bead. When the travel speed is increased, the solidification time is not enough for densification of the powder, so that the pores are increased.

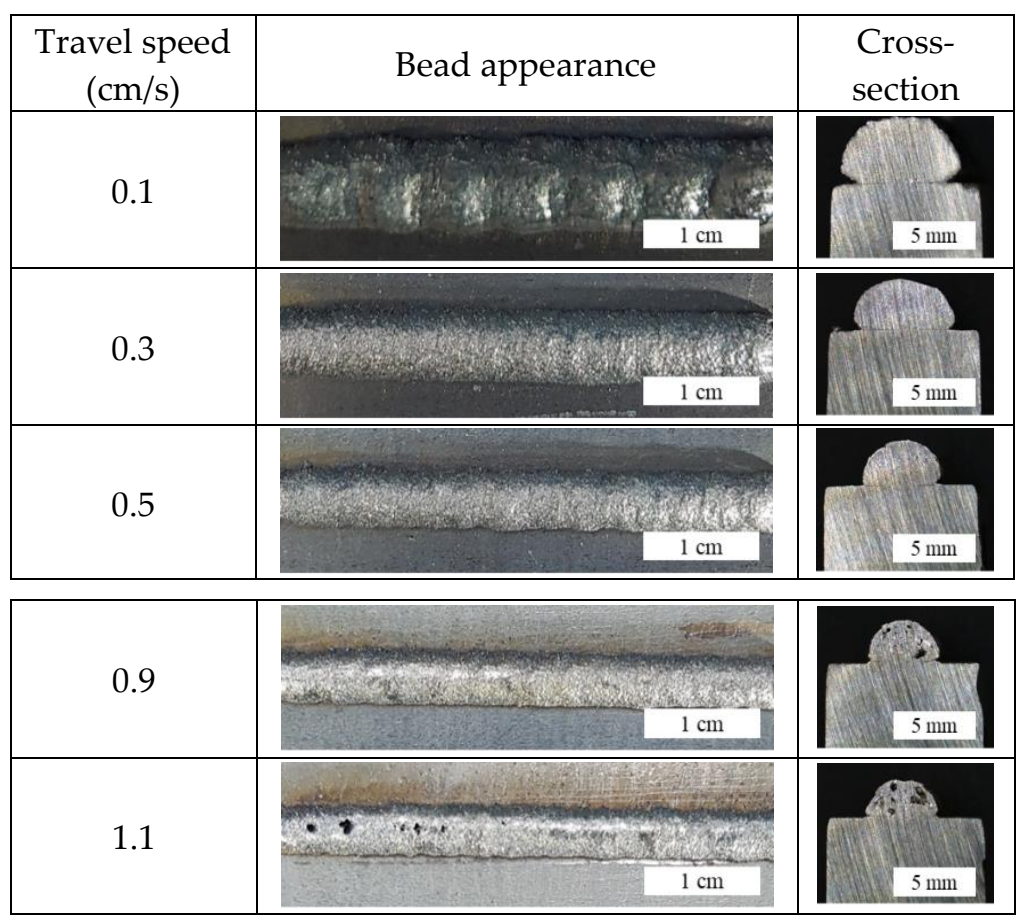

Figure 11. Bead appearance and cross-section of bead with various travel speed. 
The effect of process variables on the bead shape was investigated using Fe powder of an uneven shape and the optimal process variable interval to obtain a defect-free bead, shown in Table 5. The sound bead showed a bead ratio of $0.4-0.65$ with change of variables. According to a study [26] comparing the powder feeding method with the wire feeding method, the powder feeding method is capable of cladding under significantly more variable condition. Thus, in spite of the nonuniform powder with a wide distribution shown as Table 4, the defect-free bead could be formed.

Table 5. Optimized process parameters for the defect-free cladding bead by using irregular shaped powder. CTWD—contact tip to work-piece distance.

\begin{tabular}{cccccc}
\hline $\begin{array}{c}\text { Process } \\
\text { Parameter }\end{array}$ & $\begin{array}{c}\text { CTWD } \\
(\mathbf{m m})\end{array}$ & $\begin{array}{c}\text { Beam Shift } \\
(\mathbf{m m})\end{array}$ & $\begin{array}{c}\text { Laser Power } \\
\mathbf{( k W )}\end{array}$ & $\begin{array}{c}\text { Flow Rate } \\
(\mathbf{g} / \mathbf{m i n})\end{array}$ & $\begin{array}{c}\text { Travel Speed } \\
(\mathbf{c m} / \mathbf{s})\end{array}$ \\
\hline Value & $10-13$ & $0-0.5$ & $1.5-2$ & $20-30$ & $0.5-0.9$ \\
\hline
\end{tabular}

\subsection{Additive Manufacturing}

Figure $12 \mathrm{a}-\mathrm{c}$ show a cladding sample of the STS316/Fe functionally graded material of $100 \% \mathrm{Fe}$, $25 \%$ STS316 + 75\% Fe, 50\% STS316 + 50\% Fe, 75\% STS316 + 75\% Fe, and 100\% STS316 powder on the mild steel plate. Each powder having a composition of 100\% Fe, 25\% STS 316 + 75\% Fe, 50\% STS $316+50 \% \mathrm{Fe}, 75 \%$ STS $316+75 \% \mathrm{Fe}$, and 100\% STS 316 was cladded in total by five layers and six layers were cladded in the width direction. Figure $12 \mathrm{c}$, d shows the cross sections of the two types of deposited samples mentioned in Table 3. When the STS316 powder was directly deposited on the mild steel, there was a pore between the first layer and the substrate, as shown in Figure $12 \mathrm{~d}$ with a red circle. The defects at the interface continued to exist even if the deposition by any change of aforementioned parameters is used. However, no pores at existed the interfaces above the second layer, which was deposited between the same STS316. The spherical STS316 powder was well deposited under given conditions. As shown in Figure 12c, when the functionally graded material was prepared using Fe powder with an irregular shape and size, pores did not appear in the lower layer. However, porosity increased as the content of STS316 powder increased, which is discussed later. Therefore, Fe powder is used, and the pores of the first layer with the mild steel can be removed effectively.

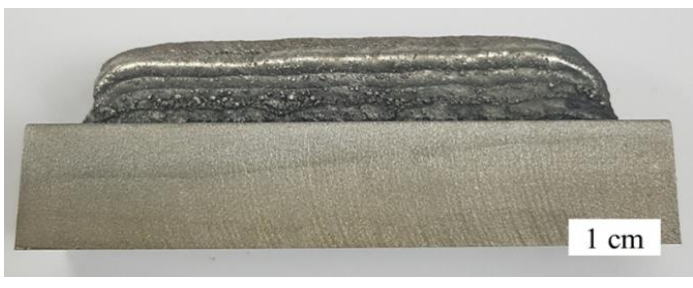

(a)

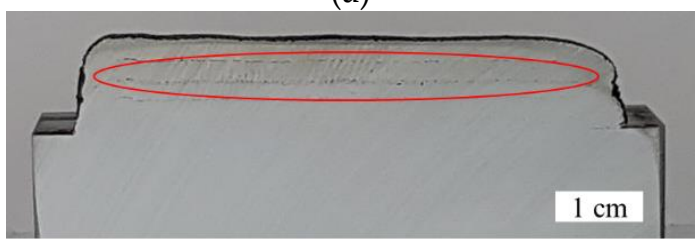

(c)

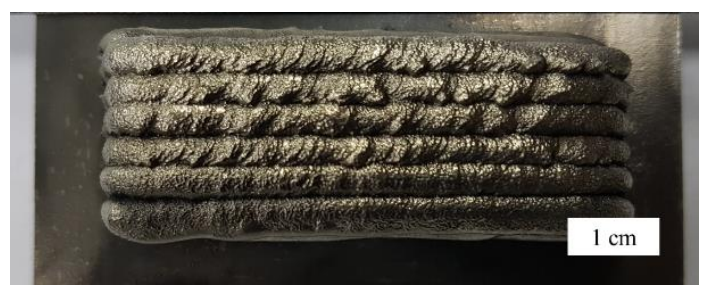

(b)

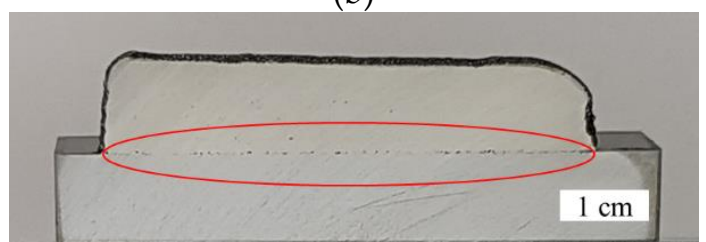

(d)

Figure 12. (a) Side view, (b) top view, (c) cross-section view of the sample after laser cladding of the STS316/Fe functionally graded material, and (d) cross-section view of the sample after dissimilar cladding between STS316 and Fe (red circle indicates pore generated region).

Figure 13 shows the microstructures of the first layer in the sample 1 and 2 by OM, respectively. Sample 1 with mild steel / STS316 interface, as shown in Figure 13a, had a distinct interface between the two materials. As a result of such an interfacial structure, cracks and peeling occurred in the 
interfacial region when deposition was performed in multiple passes. On the other hand, when the FGM was manufactured using Fe powder, it was bonded systematically at the interface, as shown in Figure 13b. In the case of FGM, thermal stress and thermal deformation can be reduced using a gradually changing thermal expansion coefficient between layers [27]. The thermal expansion coefficient of STS316 is about $17.2 \times 10^{-6} /{ }^{\circ} \mathrm{C}[28,29]$. The thermal expansion coefficient of pure Fe increases from $12.3 \times 10^{-6} /{ }^{\circ} \mathrm{C}$ to $16.2 \times 10^{-6} /{ }^{\circ} \mathrm{C}$ depending on the temperature [30]. In addition, the thermal expansion coefficient of mild steel is about $12.0 \times 10^{-6} /{ }^{\circ} \mathrm{C}[28,29]$. Fe can reduce the difference in thermal expansion coefficient compared to direct bonding of mild steel to STS316. When using $\mathrm{Fe}$, the difference in thermal expansion coefficient can be reduced compared with direct bonding of mild steel and STS316. Therefore, the interfacial bonding property between Fe and mild steel is improved compared with the interfacial bonding property between STS316 and mild steel.

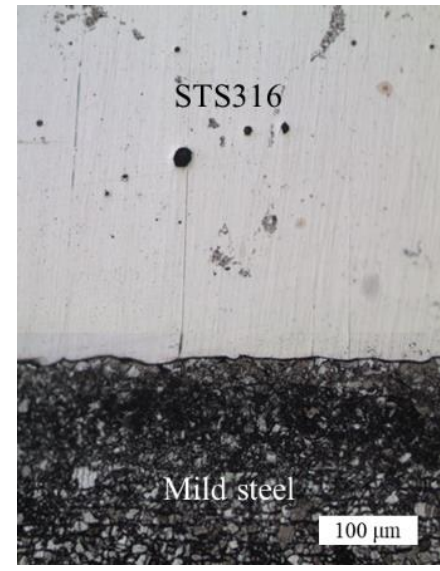

(a)

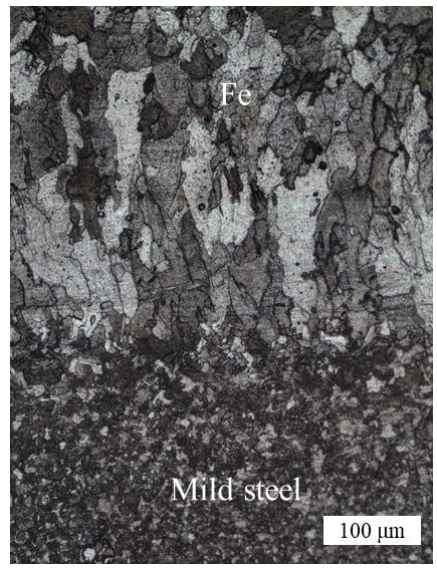

(b)

Figure 13. Microstructure of interface between (a) sample 1 and (b) sample 2.

Figure 14 shows the energy dispersive spectrometer (EDS) line scanning results of the FGM specimen. The composition of each element changes from the base material to the upper layer. $\mathrm{Cr}$ and $\mathrm{C}$ are concentrated and distributed between the interfaces, while $\mathrm{Fe}$ is relatively deficient in the region. Figure 15 shows the shaeffler diagrams, which were drawn by calculating $\mathrm{Cr}$ and $\mathrm{Ni}$ equivalent value using composition, are useful to analyze the change of phase in austenitic steel welding. Seventy-five Fe and $25 \mathrm{Fe}$ place on a martensite single phase region, $0 \mathrm{Fe}$ is a austenite single phase, and $50 \mathrm{Fe}$ is predicted a mixed phase of these two phase. In XRD analysis, as shown in Figure 16, 100Fe and 75Fe detected only ferrite/martensite peak $(\alpha)$ and $0 \mathrm{Fe}$ has a austenite peak $(\gamma)$ with relatively high intensity. Twenty-five Fe and 50 Fe has mixed peak with $\alpha$ and $\gamma$ phase, thus the result of 50Fe is opposite to the schaeffler diagram. Thus, the mixed phase region between austenite and martensite could be extended in the process condition. In the FGM, remelting and re-solidification between layers lead to change composition and phase. Especially, in these systems, the tetragonal structured sigma phase, which is usually formed at interface between $\alpha$ and $\gamma$ phase, is brittle with low toughness, resulting in fracture [15]. However, there was no XRD peak associated sigma phase at any layer of sample 2, because the fast cooling rate of the laser travel speed could control it. 


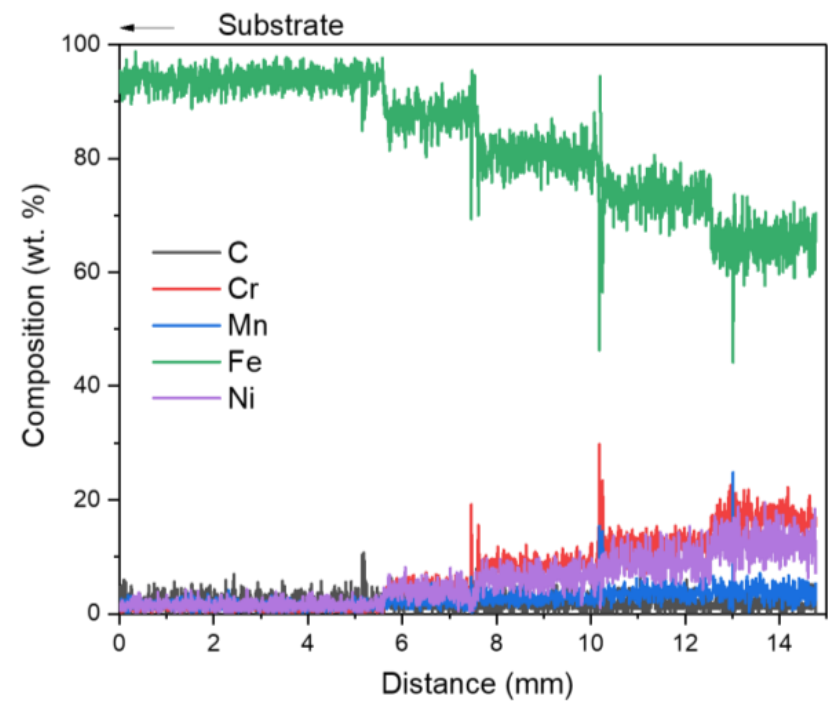

Figure 14. The result of energy dispersive spectrometer (EDS) line scanning for the mild steel/Fe(B) + STS316.

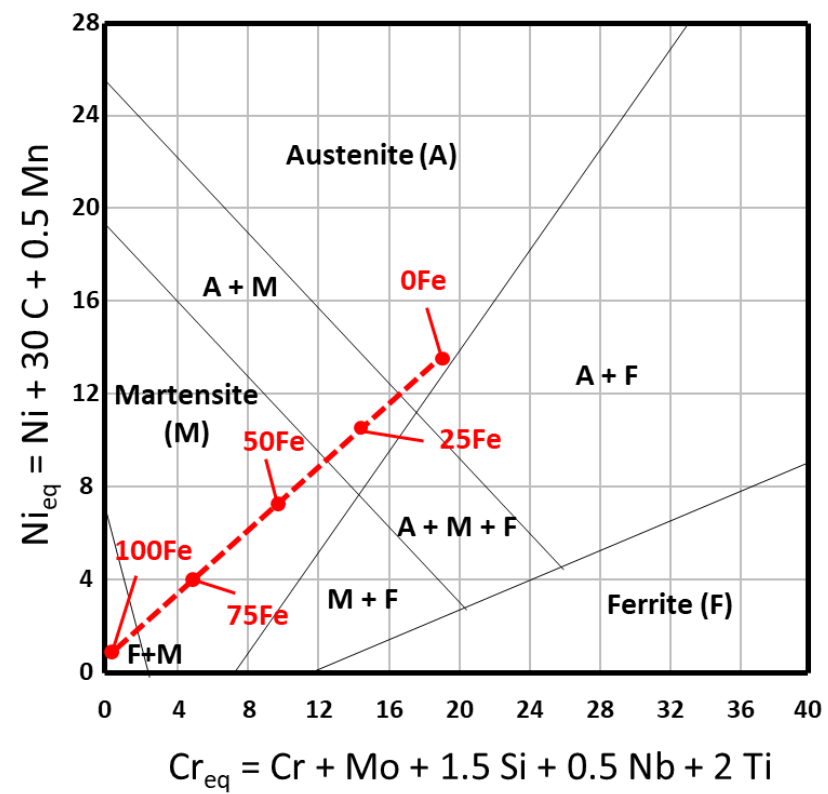

Figure 15. Schaeffler diagram representing the predicted phase of each composition. 


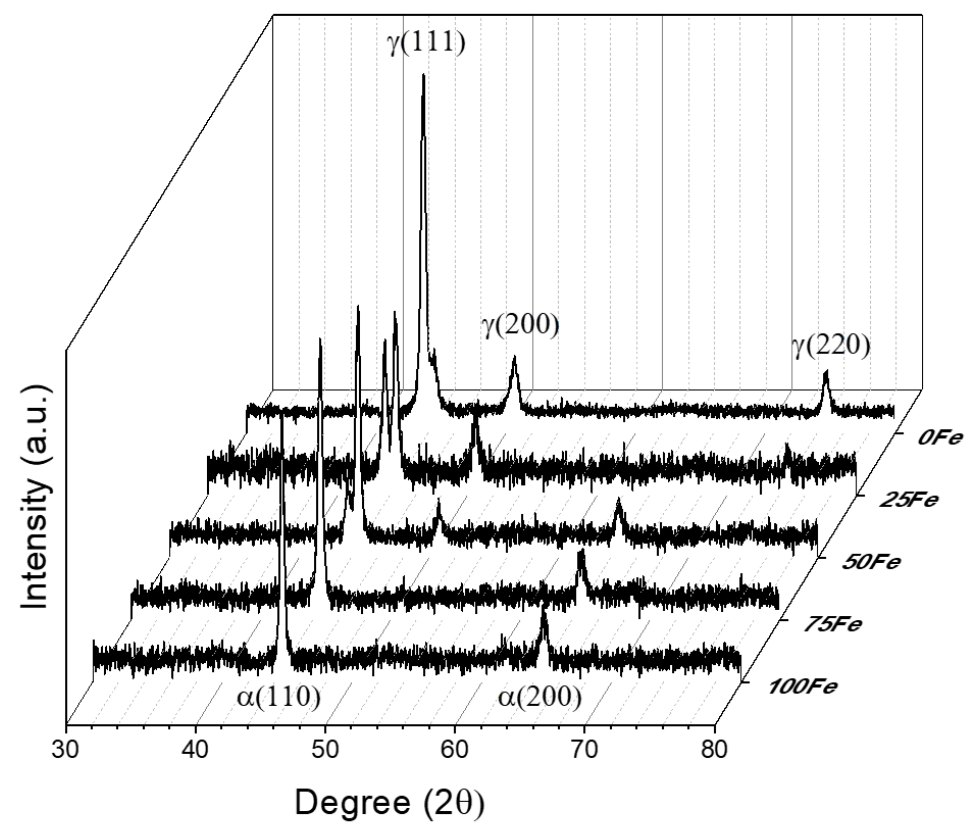

Figure 16. X-ray diffractometer (XRD) patterns at different layer along the composition gradient obtained for sample 2 .

In the case of FGM, which was deposited using a mixture of STS 316 and Fe powder, pores were present between the layers, as shown in Figure 12c with a red circle. In order to investigate the cause of pore formation in the interlayer, EDS mapping was performed on the pore region. As shown in Figure 17, the relatively high content of $\mathrm{Cr}$ and oxygen around the pores of the EDS mapping indicates that chrome oxide is formed. Carbon segregation exists at the interface of the second layer, and segregation of $\mathrm{Cr}$ is observed at the interface between each layer from the second layer. Segregation of these elements is a cause of pores and causes deterioration of physical properties at the interface. Therefore, it is necessary to reduce the pore between the interfaces by considering the contents of $\mathrm{Cr}$ and $\mathrm{C}$, in addition to changing the composition of the FGM using Fe powder.

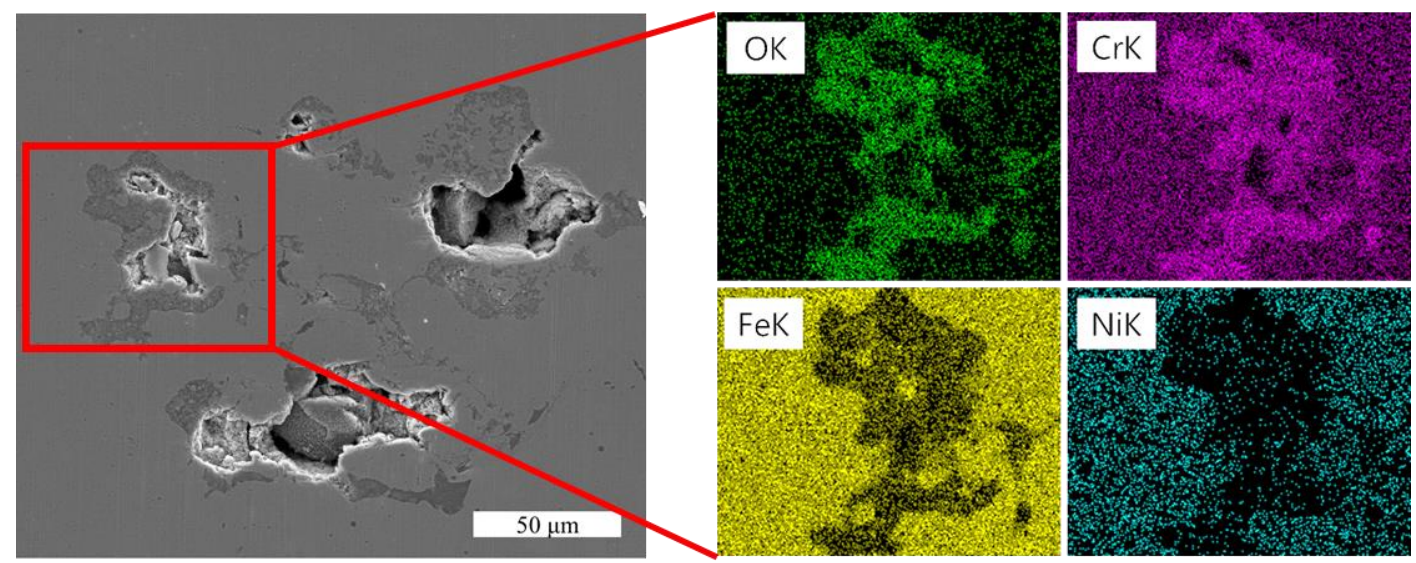

Figure 17. The result of EDS mapping for the interface pores of sample 2.

\section{Conclusions}

FGM was fabricated by laser direct metal deposition using STS316 and Fe powders. The effect of each type parameters on the physical properties was observed. The details are as follows. 
1. The process conditions for producing sound beads without humping beads, pores, and lack of fusion were derived using Fe powder with uneven size and shape.

2. The shape of the bead and the size of the pore were affected by the change of CTWD. The beam shift parameter had the effect of changing the angle of the bead, and the laser power was effective in changing the aspect ratio of the bead.

3. Low flow rates caused puckering, while excessive flow rates reduced material efficiency. In addition, humping beads were observed at slow travel speed and many pores due to rapid solidification at high travel speed.

4. The FGM samples showed gradual changes in composition and phase along the layers. In XRD analysis, any intermetallic compounds such as sigma phase was not detected.

5. When the STS316 was directly deposited on the mild steel, there were many pores and cracks at the interface. However, when the FGM was produced by using Fe and STS316 powder, defects occurring at the interface of the first layer could be removed.

6. However, as the Fe powder was mixed with STS316 powder, pores were observed between the interfaces, which resulted in the presence of chrome oxide at the interface.

Author Contributions: Investigation, S.N. and H.C.; Methodology, S.N. and Y.-M.K.; Supervision, C.K. and Y.-M.K.; Writing — original draft, S.N.; Writing—review \& editing, Y.-M.K.

Funding: This research was funded by the Korea Institute of Industrial Technology.

Acknowledgments: The authors would like to acknowledge the support provided by the Korea Institute of Industrial Technology.

Conflicts of Interest: The authors declare no conflict of interest.

\section{References}

1. Hwang, M.J.; Cho, J. Laser additive manufacturing technology review. J. Weld. Joining 2014, 32, 15-19. [CrossRef]

2. Sun, Z.; Ion, J. Laser welding of dissimilar metal combinations. J. Mater. Sci. 1995, 30, 4205-4214. [CrossRef]

3. Urbikain, G.; Perez, J.M.; López de Lacalle, L.N.; Andueza, A. Combination of friction drilling and form tapping processes on dissimilar materials for making nutless joints. Proc. Inst. Mech. Eng. Part B 2016, 232, 1007-1020. [CrossRef]

4. Goodarzi, D.M.; Pekkarinen, J.; Salminen, A. Analysis of laser cladding process parameter influence on the clad bead geometry. Weld. World 2017, 61, 883-891. [CrossRef]

5. Saqib, S.; Urbanic, R.J.; Aggarwal, K. Analysis of laser cladding bead morphology for developing additive manufacturing travel paths. Procedia CIRP 2014, 17, 824-829. [CrossRef]

6. Oliveira, U.D.; Ocelik, V.; Hosson, J.T.M.D. Analysis of coaxial laser cladding processing conditions. Surf. Coat. Technol. 2005, 197, 127-136. [CrossRef]

7. Calleja, A.; Tabernero, I.; Fernández, A.; Celaya, A.; Lamikiz, A.; López de Lacalle, L.N. Improvement of strategies and parameters for multi-axis laser cladding operations. Opt. Lasers Eng. 2014, 56, 113-120. [CrossRef]

8. Calleja, A.; Tabernero, I.; Ealo, J.A.; Campa, F.J.; Lamikiz, A.; de Lacalle, L.N.L. Feed rate calculation algorithm for the homogeneous material deposition of blisk blades by 5-axis laser cladding. Int. J. Adv. Manuf. Technol. 2014, 74, 1219-1228. [CrossRef]

9. Brentrup, G.; Dupont, J. Fabrication and characterization of graded transition joints for welding dissimilar alloys. Weld. J. 2013, 92, 72-79.

10. Shah, K.; Haq, I.U.; Khan, A.; Shah, S.A.; Khan, M.; Pinkerton, A.J. Parametric study of development of Inconel-steel functionally graded materials by laser direct metal deposition. Mater. Des. 2014, 54, 531-538. [CrossRef]

11. Wu, D.; Liang, X.; Li, Q.; Jiang, L. Laser rapid manufacturing of stainless steel 316L/Inconel718 functionally graded materials: Microstructure evolution and mechanical properties. Int. J. Opt. 2010, 2010, 1-5. [CrossRef] 
12. Reichardt, A.; Dillon, R.P.; Borgonia, J.P.; Shapiro, A.A.; Mcenerney, B.W.; Momose, T.; Hosemann, P. Development and characterization of Ti-6Al-4V to 304L stainless steel gradient components fabricated with laser deposition additive manufacturing. Mater. Des. 2016, 104, 404-413. [CrossRef]

13. Li, W.; Karnati, S.; Kriewall, C.; Liou, F.; Newkirk, J.; Brown Taminger, K.M.; Seufzer, W.J. Fabrication and characterization of a functionally graded material from Ti-6Al-4V to SS316 by laser metal deposition. Addit. Manuf. 2017, 14, 95-104. [CrossRef]

14. Li, W.; Liou, F.; Newkirk, J.; Brown Taminger, K.M.; Seufzer, W.J. Ti6Al4V/SS316 multi-metallic structure fabricated by laser $3 \mathrm{~d}$ printing and thermodynamic modeling prediction. Int. J. Adv. Manuf. Technol. 2017, 92, 4511-4523. [CrossRef]

15. Li, W.; Liou, F.; Newkirk, J.; Taminger, K.M.B.; Seufzer, W.J. Investigation on Ti6Al4V-V-Cr-Fe-SS316 multi-layers metallic structure fabricated by laser 3D printing. Sci Rep. 2017, 7, 7977. [CrossRef] [PubMed]

16. Hofmann, D.C.; Roberts, S.; Otis, R.; Kolodziejska, J.; Dillon, R.P.; Suh, J.O.; Shapiro, A.A.; Liu, Z.K.; Borgonia, J.P. Developing gradient metal alloys through radial deposition additive manufacturing. Sci. Rep. 2014, 4, 5357. [CrossRef] [PubMed]

17. Zhang, C.; Zhang, H.; Wu, C.; Zhang, S.; Sun, Z.; Dong, S. Multi-layer functional graded stainless steel fabricated by laser melting deposition. Vacuum 2017, 141, 181-187. [CrossRef]

18. Li, W.; Yan, L.; Chen, X.; Zhang, J.; Zhang, X.; Liou, F. Directed energy depositing a new Fe-Cr-Ni alloy with gradually changing composition with elemental powder mixes and particle size' effect in fabrication process. J. Mater. Process. Technol. 2018, 255, 96-104. [CrossRef]

19. Fatima, S.; Khan, M.; Jaffery, S.H.I.; Ali, L.; Mujahid, M.; Butt, S.I. Optimization of process parameters for plasma arc welding of austenitic stainless steel (304 L) with low carbon steel (A.-36). Proc. Inst. Mech. Eng. Part L 2015, 230, 640-653. [CrossRef]

20. Klueh, R.; King, J. Austenitic stainless steel-ferritic steel weld joint failures. Weld. J. 1982, 61, 302-311.

21. Dupont, J.N. Microstructural evolution and high temperature failure of ferritic to austenitic dissimilar welds. Int. Mater. Rev. 2013, 57, 208-234. [CrossRef]

22. Chuaiphan, W.; Chandra-Ambhorn, S.; Sornil, B.; Bleck, W. Microstructure, mechanical and corrosion behaviour of dissimilar weldments between AISI 304 stainless steels and AISI 1020 carbon steels produced by gas tungsten arc welding using different consumables. Key Eng. Mater. 2009, 410-411, 533-541. [CrossRef]

23. Li, W.; Zhang, J.; Zhang, X.; Liou, F. Effect of optimizing particle size on directed energy deposition of functionally graded material with blown pre-mixed multi-powder. Manuf. Lett. 2017, 13, 39-43. [CrossRef]

24. Hwang, J.H.; Shin, S.S.; Jung, G.I.; Kim, S.W.; Kim, H.D. A study on the characteristics of laser deposition surface and cross-section for metal powder. J. Weld. Joining 2016, 34, 17-22. [CrossRef]

25. Qi, H.; Mazumder, J.; Ki, H. Numerical simulation of heat transfer and fluid flow in coaxial laser cladding process for direct metal deposition. J. Appl. Phys. 2006, 100. [CrossRef]

26. Kam, D.H.; Kim, Y.M.; Kim, C. Recent studies of laser metal 3D deposition with wire feeding. J. Weld. Joining 2016, 34, 35-40. [CrossRef]

27. Noda, N. Thermal stresses in functionally graded materials. J. Therm. Stress. 1999, 22, 477-512. [CrossRef]

28. Charde, N.; Yusof, F.; Rajkumar, R. Material characterizations of mild steels, stainless steels, and both steel mixed joints under resistance spot welding (2-mm sheets). Int. J. Adv. Manuf. Tech. 2014, 75, 373-384. [CrossRef]

29. Song, Y.A.; Park, S. Experimental investigations into rapid prototyping of composites by novel hybrid deposition process. J. Mater. Process. Technol. 2006, 171, 35-40. [CrossRef]

30. Cleaves, H.E.; Hiegel, J.M. Properties of high-purity iron. J. Res. Natl. Bur. Stand. 1942, 28, $643-667$. [CrossRef]

(C) 2018 by the authors. Licensee MDPI, Basel, Switzerland. This article is an open access article distributed under the terms and conditions of the Creative Commons Attribution (CC BY) license (http:/ / creativecommons.org/licenses/by/4.0/). 